\title{
Güç Sistemlerinde Aşırı Akım Koruma Koordinasyon Modelinin Oluşturulması, Benzetimi ve Optimizasyonu
}

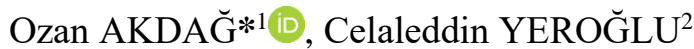

${ }^{1}$ İnönü Üniversitesi Mühendislik Fakültesi, Bilgisayar Mühendisliği, Malatya, Türkiye

2İnönü Üniversitesi Mühendislik Fakültesi, Bilgisayar Mühendisliği, Malatya, Türkiye

Geliş / Received: 07/09/2018, Kabul / Accepted: 08/03/2019

\begin{abstract}
$\ddot{O} z$
$\mathrm{Bu}$ yayında, güç sistemlerindeki çeşitli teçhizatların korunmasında kullanılan yönlü ve yönsüz aşırı akım rölelerinin koordinasyon benzetimi yapılmıştır. Çalışmada rölelerin optimum ayarlarının bulunmasında, PSO (Particle Swarm Optimizastion) ve CSA (Crow Search Algorithm) kullanılmıştır. Bu algoritmalar ile bulunan röle ayarları, modellemesi yapılan güç sistemindeki sanal modelde aşırı akım rölelerine girilmiştir. Daha sonra modellenen güç sisteminde, arıza akım senaryoları oluşturularak rölelerin bu arızalara tepkisi analiz edilmiştir. Böylece PSO ve CSA algoritmalarının güç sistemlerindeki optimum röle ayarlarının bulunmasındaki başarısı test edilmiştir.
\end{abstract}

Anahtar Kelimeler: Aşırı akım rölesi, Güç sistemleri analizi, Optimum röle ayarı, Optimizasyon

Overcurrent Protection Coordination Models in Power Systems, Simulation and Optimization

\section{Abstract}

In this paper, coordination simulations of directional and non-directional overcurrent relays, which are used to protect various equipment in power system, is practiced. PSO (Particle Swarm Optimization) and CSA (Crow Search Algorithm) are used to find the optimal relay settings. The relay settings, found with these algorithms, have been entered into the overcurrent relays in the virtual model of the power system. Then, fault currents scenarios are generated in the virtual model and fault responses of the relays are analyzed. Thus, the success of PSO and CSA algorithms in finding optimal relay settings in power systems has been tested.

Keywords: Overcurrent relay, Analysis of power systems, Optimum relay setting, Optimization

\section{Giriş}

Gelişen dünyamızda, elektrik enerjisi gün geçtikçe önemini artıran bir olgudur. Enerjinin her geçen gün artan kapasitesi ile üretim tesislerinden tüketicilere taşınması konusu önemli bir durum haline gelmiştir. Enerjinin üretimden tüketime olan bu sürecinde kararlılık, süreklilik, kalite, koruma vb. gibi konular üzerinde son y1llarda iyileştirici ve geliştirici birçok çalışma yapılmaktadır. Bu çalışma konularından biri olan enerjinin devamlılığı ve koruma konusu önemli bir güç sistemi mühendisliği problemidir. Güç sistemlerinde koruma bir bütün olarak birçok koruma rölesi (mesafe koruma rölesi, diferansiyel, aşırı akım vb...) ile sağlanır. Bu çalışmada genel olarak, güç sistemlerinde güç transformatörleri ve enerji iletim hatlarının korunmasında kullanılan aşırı akım röleleri konusu ele alınmıştır. Öncelikle çalışmada örnek bir güç sistemi modeli oluşturulmuştur. Daha sonra bu modelde aşırı akım röle koordinasyonu yapılırken, rölelerin optimum koruma ayarlarının bulunmasında optimizasyon algoritmalarından yararlanılmıştır. Optimizasyon algoritmaları ile bulunan ayarlar, sanal modeldeki aşırı akım rölelerine girilerek, modelde oluşturulan arıza akım senaryoları ile test edilmiştir. Güç sisteminin sanal modeli DigSilent adlı güç sistemleri analiz programı ile oluşturulmuştur. Sonuç olarak bu çalışma ile gerçek zamanlı bir sistemde herhangi bir risk göze almadan ve sisteme zarar vermeden, sanal bir modelde aşırı akım koruma koordinasyonu yapılarak 
gerçek zamanlı sistemde kullanılabilecek parametrelerin elde edilebileceği gösterilmiştir.

\section{Materyal ve Metot}

\subsection{Așırı Akım Rölesi}

Güç sistemlerinde çeşitli nedenlerden dolayı bir arıza meydana geldiğinde, oluşan arıza akımları genel olarak güç sistemindeki teçhizatların nominal çalışma şartları durumundaki akan akımdan daha büyük olur (Karababa, 2013). Arıza oluştuğunda, oluşan bu arıza akımlarından güç sistemi teçhizatları korunmalıdır. Güç sistemlerinde transformatör, hat vb. gibi teçhizatların korunması aşırı akım röleleri ile sağlanır (Karababa, 2013). Aşırı akım röleleri ani ve zaman gecikmeli röleler olarak 2 adet çalışma karakteristiğine göre ayarlanır. Ülkemizde güç sisteminde aşırı akım röleleri genel olarak faz-faz arızalarına karşı ters zamanlı, faz-toprak arızalarına ise sabit zamanlı olarak ayarlanır. Aşırı akım röleleri gücün akışına göre ileri ya da geri yönde koruma yapabilir. Güç sistemlerinde ileri yön, güç akışının baradan hatta doğru olduğunu ifade ederken, geri yön ise güç akışının baraya doğru olduğunu ifade eder. Yönlü koruma arıza noktasının farklı yerlerden beslediği sistem koşullarında kullanılır. Yönlü aşırı akım röleleri diğer yönsüz aşırı akım rölelerinden farklı olarak gerilim bilgisini de alırlar. Daha sonra gerilim ve akım arasındaki açıyı ölçerek yön tayini yaparlar.

\section{2. Önceki Çalışmalar}

Optimizasyon algoritmaları çeşitli mühendislik dallarında olduğu gibi (Özel, 2006; Özyön vd., 2011) güç sistemlerinde de problemlerin çözümünde kullanılır. $\mathrm{Bu}$ güç sistemi problemlerden biri olan aşırı akım röle koordinasyonu konusunda optimizasyon algoritmalarının kullanıldığı çalışmalardan bazıları şöyle özetlenebilir; Chelliah ve arkadaşları kaotik diferansiyel evrim algoritması kullanarak, IEEE test bara sistemlerinde yönlü aşırı akım röle koordinasyonu için optimal röle ayarları bulmuşlardır (Chelliah vd., 2014). Zeineldin ve arkadaşları modifiye edilmiş PSO algoritmas1 kullanarak IEEE 14 bara test sisteminde aşırı akım röle koordinasyonu yapmışlardır (Zeineldin vd., 2006). Matlagh ve Mazlumi 30 baralık bir güç sisteminde genetik algoritma ve PSO ile geliştirdikleri hibrid algoritma ile optimal aşırı akım röle koordinasyonu yapmışlardır (Matlagh ve Mazlumi, 2014). Alipour ve arkadaşları 15 baralık bir güç sisteminde geliştirilmiş grup arama algoritması kullanarak yönlü aşırı akım koordinasyonu yapmışlardır (Alipour vd., 2015). Vijayakumar ve Nema, PSO algoritması ile bir güç sistemindeki aşırı akım rölelerinin optimal ayarlarını bulmuşlardır (Vijayakumar ve Nema, 2008). Abubekir ve arkadaşları Lig Şampiyonluk Algoritması ile bir transformatör merkezine ait yönsüz aşırı akım rölelerinin ayarlarını bulmuşlardır. Daha sonra buldukları bu ayarlar1 DigSilent ile modellemesini yaptıkları güç sisteminde test etmişlerdir (Abubekir vd., 2017). Singh ve arkadaşları bir güç sistemindeki yönlü aşırı akım rölelerinin ayarlarını diferansiyel evrim algoritması kullanarak bulmuşlardır. Daha sonra bu ayarların doğruluğunu DigSilent ile modellemesini yaptıkları güç sisteminde test etmişlerdir (Singh vd., 2013).

\section{3. Örnek Güç Sisteminin}

ModeliGüç sistemlerinde aşırı akım röle koordinasyonundaki temel koruma amac1 seçici, güvenli ve istenilen zamanda uygun ayarların yapılması ile sağlanır. Aşırı akım rölelerinde zaman arama ayarının (TMS) ve rölelerin başlatma akımı (PS) ayarlarının bulunması aşırı akım röle koordinasyonunun temelidir. Son yıllarda güç sistemlerinde daha optimum güvenilir ayarların bulunması için optimizasyon teknikleri sıkça uygulanmaktadır (Chelliah vd., 2014). Bu yayında Şekil 1'de verilen 154/34.5 kV örnek bir güç sistemindeki aşırı akım rölelerinin ayarlarının bulunması, PSO ve CSA algoritması ile yapılarak bu iki optimizasyon algoritması karşılaştırılmıştır. Bu modelde Türkiye İletim Sisteminde kurulu olan sistemlerindeki $154 / 34.5 \quad \mathrm{kV}$ trafo 
merkezlerinin temel yapısı referans alınmıştır. Şekil 1'de verilen 4 adet röleden sadece 4 nolu röle yönlü röle iken diğer 3 röle yönsüz aşırı akım rölesidir. Şekil 1'de güç trafosunun gücü 31,25 MVA'dir. Bu trafoya ait \%uk (kısa devre gerilimi) 12,7'dir.
Burada trafonun primer kisminda bulunan akim trafosu 400/5 oranında iken sekonder tarafinda bulunan akım trafosu 2000/5 oranındadır. $34,5 \mathrm{kV}$ 'lik fiderdeki akım trafo oranlar1 ise $600 / 5$ ' dir.

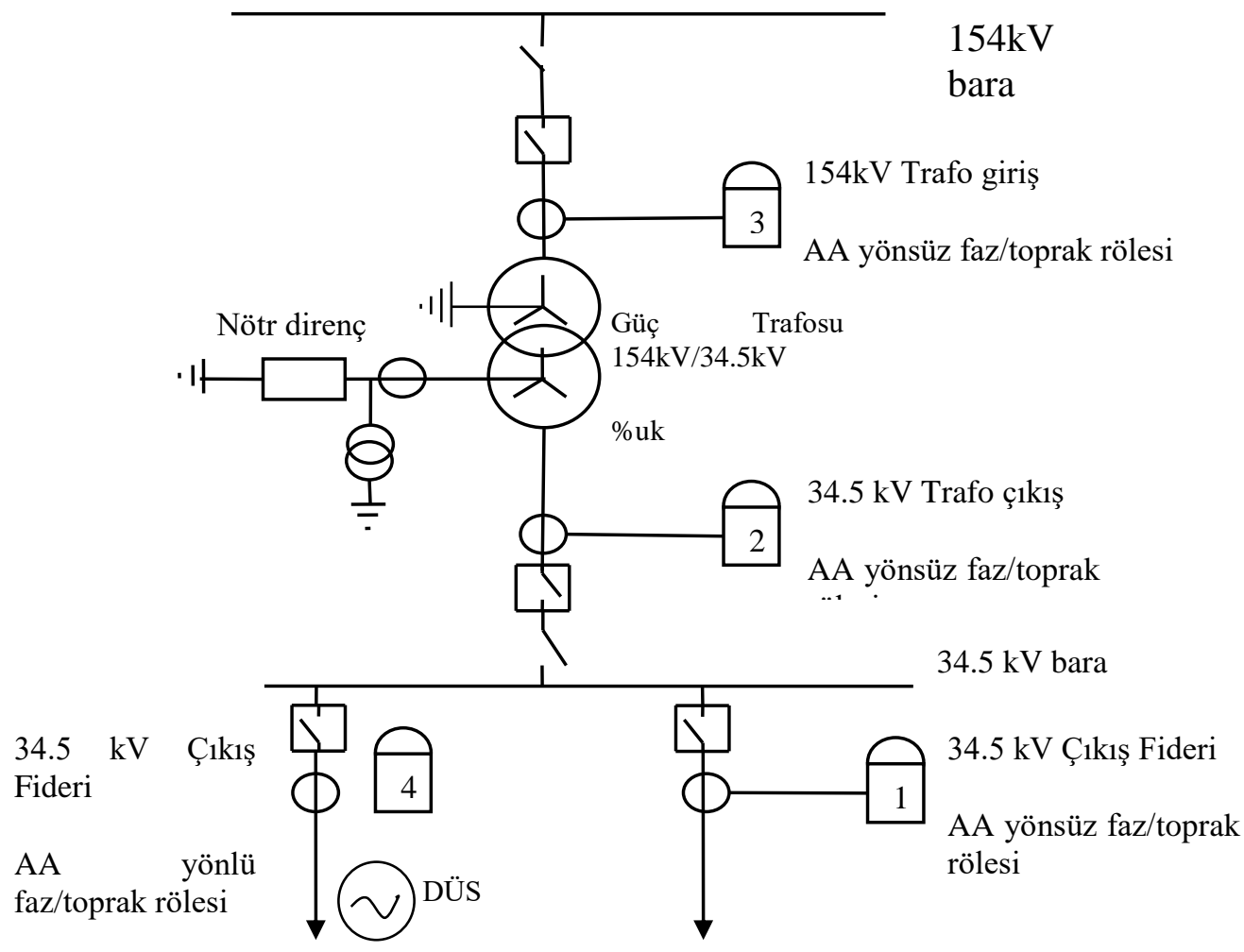

Şekil 1. Örnek güç sistemi

\subsection{Aşırı Akım Röle Koordinasyonu Probleminin Formülasyonu}

Şekil 1'de verilen güç sisteminde: Röle1, röle2, röle3 ve röle4 gruplarında bulunan aşırı akım rölelerinin faz-faz arızaları için aşırı akım röle koordinasyonu yapılmıştır. Faz-faz arızalarında aşırı akım röleleri ters zaman eğrisine göre ayarlanır. Ters zaman eğrisi Şekil 2'de görüldüğü gibidir. Ters zaman eğrisi iki değer yardımıyla seçilir. Bu değerler başlatma akım değeri $P S$ ve zaman sabiti TMS'dir. Aşırı akım röle koordinasyonunda kullanılacak amaç fonksiyonu denklem 1'de gösterildiğgi gibidir. Amaç Fonksiyonu $=\min \sum_{i=1}^{n}(t i) . m$
Burada, n; güç sistemindeki aşırı akım röle sayısını, $t i$; her bir aşırı akım rölesinin çalışma zamanını, $m$ ise güç sistemindeki arıza olma olasılığını gösterir $(m=1)$. Burada faz-faz arizalarda toplam minimum zaman bulunurken rölelerin standart ters zamanlı eğrisi dikkate alınmıştır (Pınar, 1985). Faz-toprak arızalarında ise sabit zamanlı eğri kullanılır. Burada güç sistemi nötr direnç tarafindan 1000A'e sinırlandırılmıştır. Bu yüzden; Röle 3 ve 4, 60-80A arasında 1s'de açacak şekilde, Röle2 100A'de 2s'de açacak şekilde ayarlanır. 154 $\mathrm{kV}$ güç sistemi tarafında ise toprak ayarı yapılmaz. $\mathrm{Bu}$ çalışmada faz-toprak koordinasyonunda standart veriler seçildiğinden (Enerji Bakanlı̆̆ı, 2017), sadece faz-faz aşırı akım röle koordinasyonu yapılmıştır. Şekil 1'de görülen röle 4'ün olduğu $34,5 \mathrm{kV}$ fider, arızayı çift taraflı 
besleyebilir. Çünkü bu fiderde küçük çapta bir dağıtılmış üretim santralinin olduğu durum düşünülmüştür (Muangchareon vd., 2013). Bu 4 nolu röle diğer rölelerde (1-2-3 nolu) olduğu gibi ayarlanır. Sadece bu rölede akım ve gerilim bilgileri arasındaki açıya göre yön tayini yapılır.

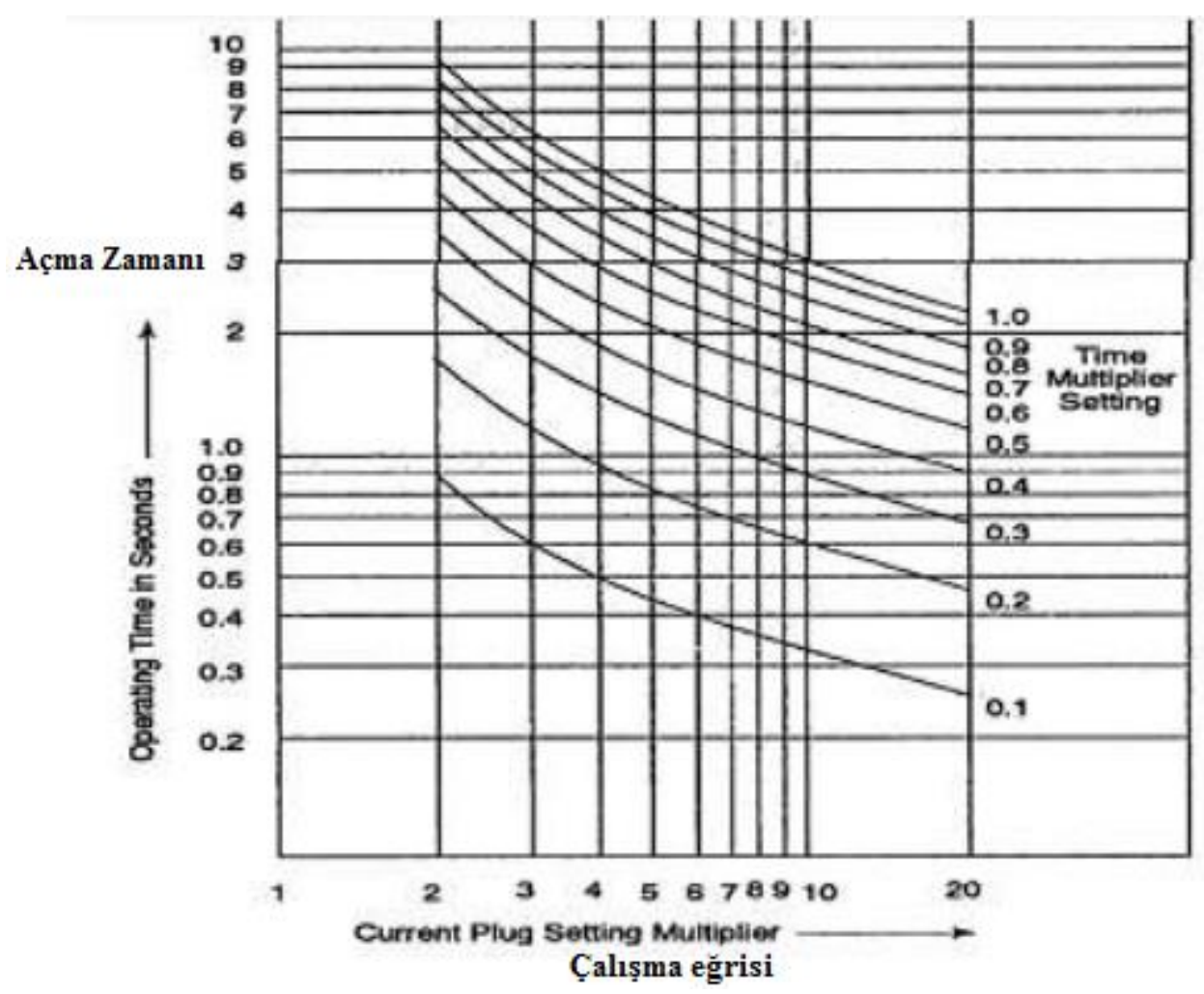

Şekil 2. Standart ters zaman eğrisi (Pınar, 1985)

Standart ters zaman eğrili çalışma karakteristiğine sahip, bağıntı denklem 2'de görüldüğü gibidir (Pınar, 1985).

$\mathrm{t}_{\mathrm{i}}=\frac{0,14 \cdot \mathrm{TMS}}{\left(\frac{\mathrm{IKD}}{P S_{i}}\right)^{0,02}-1}$

Denklem 2'de IKD kısa devre akım değeridir. $\mathrm{Bu}$ çalışmada $I K D$ değeri $154 \mathrm{kV}$ taraf için 1263 A seçilirken $34.5 \mathrm{kV}$ tarafi için 5634 A seçilmiştir.PS değerleri röle1 ve röle2 için Denklem (3) ve(4) ile bulunur. Röle3 ve röle4 için akım trafosunun primer akımı, başlatma akımı olarak (600/5) 600 A seçilir.

$$
\begin{aligned}
& \mathrm{PS}_{154 \mathrm{kV}}=\frac{32,5 \mathrm{MVA}}{\sqrt{3} \times 154 \mathrm{kV}}=117 \mathrm{~A} \\
& \mathrm{PS}_{34,5 \mathrm{kV}}=\frac{32,5 \mathrm{MVA}}{\sqrt{3} \times 34,5 \mathrm{kV}}=523 \mathrm{~A}
\end{aligned}
$$

Problemin Kisitları;

Aşırı akım röle koordinasyonunda, optimum ayar değerlerini bulmada kullanılan kısıtlar Türkiye iletim sisteminde kullanılan standart değerlere göre belirlenmiştir.

1. Kisit:

$$
\begin{gathered}
\operatorname{timin} \leq t i \leq \operatorname{timax}(0.4 \mathrm{sn} \leq t i \\
\leq 2 \mathrm{sn})
\end{gathered}
$$

$\mathrm{Bu}$ kısıt aşırı akım rölelerinin bir arıza akımında ne kadar sürede açacağını gösterir. Güç sisteminde ilk önce $34,5 \mathrm{kV}$ fiderler sonra sırasıyla güç transformatörünün sekonder ve primer tarafları devre dışı kalır. Her bir aşırı akım rölesi kendi arasında 0,50,8 sn zaman fark1 birakılarak $t 4, t 3 \leq$ $t 2 \leq t 1$ siralanır. $34,5 \mathrm{kV}$ fiderlere ait rölelerde ise $t 4, t 3$ zamanları arasında herhangi bir kısitlamaya gerek yoktur.

2. K1sit: TMSmin $\leq T M S \leq T M S \max$, (Bu kisit değerleri Şekil 2' ye göre örnek 
trafo merkezi modeli temel alınarak aşağıdaki gibi seçilmiştir).

$$
\begin{aligned}
& \text { Röle1 için } 0.55 \leq T M S \leq 0.67 \\
& \text { Röle } 2 \text { ççin } 0.36 \leq T M S \leq 0.47 \\
& \text { Röle3 için } 0.15 \leq T M S \leq 0.27 \\
& \text { Röle4 için } 0.15 \leq T M S \leq 0.27
\end{aligned}
$$

3. Kısıt: $P S=$ Arıza başlatma akımı, (Bu merkezlerinde başlatma akım değerleri sınır kısıt değerleri Denklem (3) ve (4) temel değerlerinden biraz daha fazla seçilebilir alınarak aşağıdaki gibi seçilmiştir.Trafo (Abubekir vd., 2017)).

$$
\begin{aligned}
& \text { Röle } 1 \text { ç̧in PS }=117 \leq P S \leq 128 \\
& \text { Röle } 2 \text { ç̧in PS }=523 \leq P S \leq 545 \\
& \text { Röle3 } i \text { çin PS }=600 \leq P S \leq 610 \\
& \text { Röle4 için PS }=600 \leq P S \leq 610
\end{aligned}
$$

\subsection{PSO Algoritması}

PSO algoritması, kuş sürülerinin sosyal davranışlarından ilham alınarak geliştirilmiştir (Shi, 2001). Sürü olarak hareket eden kuşların rastgele hareketler ile belli bir bölgede yiyecek ararken, birbirlerini takip ederek yiyecek olan bölgeye yoğunlaşırlar. Burada her bir kuş'a parçacık, parçacıkların bir araya gelmesine de sürü (swarm) denilir. Her bir parçacık bir önceki konumunu güncelleyerek yeni konumunu bulur. Aynı şekilde bu güncelleme işlemi sürü içindeki en iyi parçacıkla da kıyaslanarak sürü içi en iyi konum bulunur (Shi, 2001). PSO algoritmasının temel yaklaşımı Şekil 3'te görselleştirilmiştir.Bu çalışmada PSO algoritması ile optimum PS ve TMS değerlerini bulmak için sirasıyla Denklem (5-7) takip edilir. Her bir parçacığın yer değiştirmesi konumundaki ve hızındaki değişikliklere dayanır.

$p_{i}^{k+1}=p_{i}^{k}+v_{i}^{k+1}$
Burada $p_{i}^{k}$ parçacığının ilk konumudur $(k, k+1$ iterasyon say1s1), daha sonra bu değer hız değeri $v$ ile $p_{i}^{k+1}$ konumuna güncellenir.

$$
\begin{aligned}
& v_{i}^{k+1}=\mathrm{w} \cdot \mathrm{v}_{\mathrm{i}}^{\mathrm{k}}+\mathrm{c}_{1} \cdot \text { unifrnd }(0,1) \mathrm{x}\left(p_{\text {besti }}^{i}-\right. \\
& \left.p_{i}^{k}\right)+c_{2} \cdot \text { unifrnd }(0,1) x\left(g_{\text {best }}-p_{i}^{k}\right)
\end{aligned}
$$

Burada $p_{\text {besti }}$ i. Parçacı̆̆ın en iyi çözümü iken $g_{\text {best }}$ sürünün en iyi konumudur. Unifrnd $(0,1) \quad 0$ ile 1 arası rassal sayılar üretir. c1, c2 ise ağırlık katsayılarıdır ve bu değerler bu çalışmada 1 olarak seçilmiştir. w ise ağırlık fonksiyonudur değeri 0.8 'dir. Denklem 4'de hız değeri maksimum bir değere sınırlandırılmıştır. Bu değer denklem 5'de görüldüğü gibidir. Buradaki as ve $u s$ değerleri sürü içindeki parçacıkların alacağ 1 değerlerin maksimum (us), minimum (as) alacağı değerledir.

$v \max =(u s-a s) / 2$ 


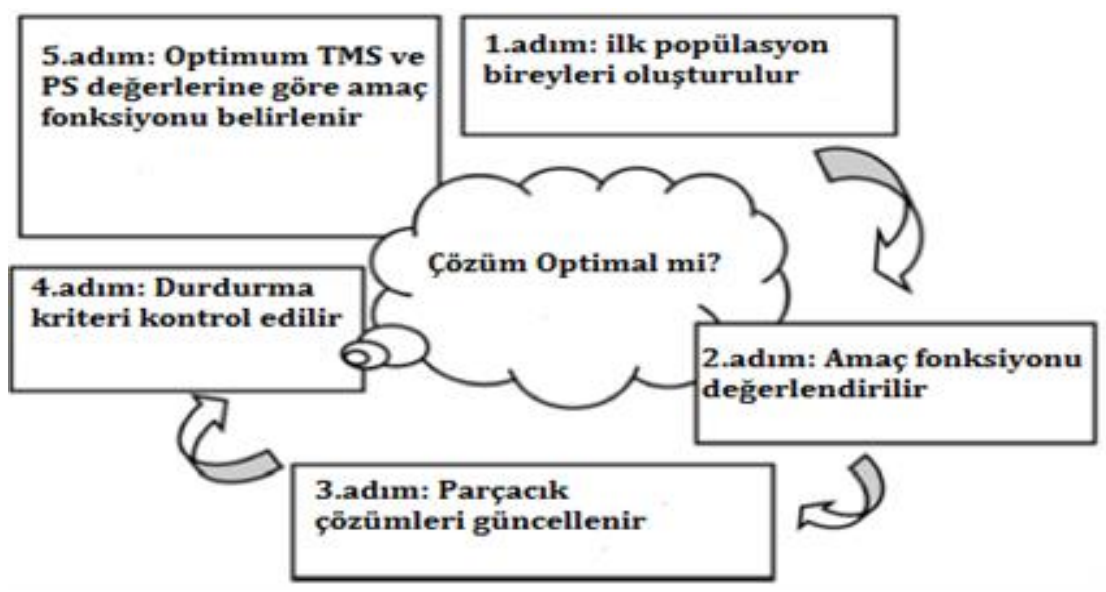

Şekil 3. PSO algoritmasının temel taslağının görünümü

\subsection{CSA Algoritması}

Kargalar kuş familyasının en zeki hayvanlarından biridir. Vücut oranlarına göre kargaların beyinleri büyüktür. Kargalar diğer kuşlardan farklı olarak daha planlı hareket ederler. Yiyeceklerini gizleme diğer kuşlardan yiyecek çalma becerilerine sahiptir. Kargaların saklandıkları yeri hatırlama, yiyecek ararken birbirlerini izleme ve kendi bölgelerini savunma gibi davranışlarını gözlemleyen Askarzadeh, CSA algoritmasını sunmuştur (Askarzadeh, 2016). CSA algoritmasının temel yapısı aşağıdaki gibi sıralanır;

- Kargalar sürü şeklinde yaşarlar

- Kargalar saklandığ saklarlar

- Kargalar hırsızlık yapmak için birbirlerini takip ederler

- Kargalar hırsızlı yapmaya gelen kargalara karşı kendini korurlar

Birçok karganın olduğu d-boyutlu bir ortam olduğu varsayılsın. Kargaların sayısı $N t$, her iterasyonda ki kargaların konum vektörleri $x^{i, \text { iter }}(\mathrm{i}=1,2, \ldots, N t)$ olsun, bu durumda

$x^{i, \text { iter }}=\left[x_{1}^{i, i t e r}, \ldots, x_{d}^{i, i t e r}\right]$

yazılabilir. Her karga eski pozisyonunu hafizasında saklayabilir. Her iterasyondaki karganın hafızasındaki pozisyon $m^{i, i t e r}$ olarak verilir. Bu $m$ olarak verilen ifade ilgili karganın şimdiye kadarki en iyi pozisyonudur. Kargalar daha sonra hareket ederek her aramada en iyi besin kaynağına gider. Her $i$. karga $j$. Kargayı takip ederek, $j$. karganın gizlendiği yere gider. Bu çalışmada optimum röle ayarı bulunurken takip edilen yol izlenecek olursa;

Karga j, karga i'nin kendini takip ettiğini bilir ve kendi sığınağını korumak için i. kargayı kandırarak başka konuma götürür. Sonuç olarak aşağıdaki bağıntı ile bu durum verilebilir;

$x^{i, i t e r+1}=$

$\left\{\begin{array}{c}x^{i, i t e r}+r_{i} x f l^{i, i t e r} x\left(m^{j, i t e r}-x^{i, i t e r}\right) r_{j} \geq A P^{J, i t e r} \\ \text { a rastgele pozisyon otherwise }\end{array}\right.$

(9)

Burada $r j(0-1)$ arası rassal bir sayıdır. AP ise iterasyondaki $j$. karganın farkındalık olasılığını verir. Karga arama algoritmasının sahte kodu şekil 4'de görüldüğü gibidir. Bu çalışmada karga sürüsünün arama tekniği optimum röle ayarlarını bulmada kullanılmıştır. CSA algoritmasının adımları sırası ile aşağıdaki gibi uygulanmıştır.

1.adım: $\mathrm{Bu}$ aşamada problemin parametreleri belirlenir. Sürü boyunu $=50$, iterasyon sayıs 1 $=50$, problem boyutu (röle sayıs1) $=4$ seçilmiştir.

2.adım: Her bir karganın ilk hafiza verileri rastgele verilir (karga hafiza verileri, röle 
zamanı değerlerine karşılık gelir ve röle 5.adım: Eğer bir karganın önceki verileri kısıtlarına göre rastgele seçilir).

3.adım: 2. Adımdaki üretilen verilere göre amaç fonksiyonu üretilir.

4.adım: 3.adımdaki verilere göre yeni pozisyonlar üretilir. uygunsa o değer ile devam edilir, değilse değer değiştirilir.

6.adım: 5.adım verilerine göre hafiza verileri güncellenir. Uygun olan değerler hafizaya alınir.

7.adım: $\mathrm{Bu}$ adımda sonlandırma kriteri devreye girer. Değerler uygunsa sonlandırma yapılır. Değilse 4. Adıma gidilir.

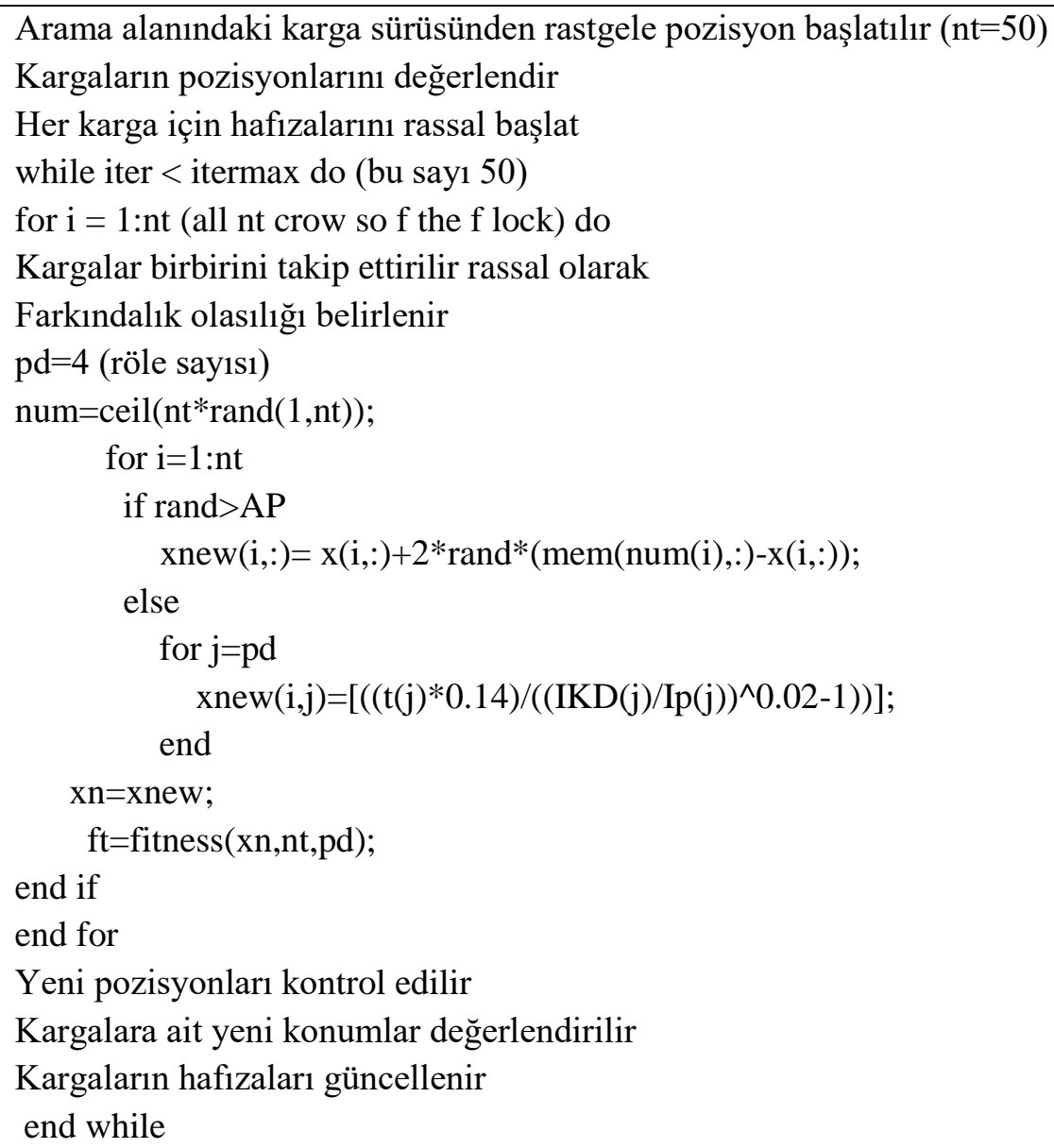

Şekil 4. CSA algoritmasının sahte kodu

\section{Bulgular}

$\mathrm{Bu}$ çalışmanın sonuçları iki kısımda ele alınmıştır. İlk kısımda optimizasyon algoritma sonuçları verilerek yorumlanmıştır. İkinci kısımda ise optimizasyon algoritmaları sonucu bulunan değerler DigSilent programında modellemesi yapılan aşırı akım rölelere girilerek, yine sanal modelde oluşturulan arıza senaryoları ile aşırı akım rölelerinin performansları analiz edilmiştir.

\subsection{PSO ve CSA Algoritmalarının Sonuçları}

PSO ve CSA algoritmaları ile bulunan aşırı akım rölelerinin optimum değerleri Tablo 1'de verildiği gibidir. Tabloda aşırı akım rölelerin toplam açma zamanlarının yakınsamaları da, görülmektedir. 
Tablo 1. PSO ve CSA algoritması sonuçları

\begin{tabular}{|c|c|c|c|c|c|c|}
\hline & \multicolumn{3}{|c|}{ CSA } & \multicolumn{3}{c|}{ PSO } \\
\hline Röle & TMS & PS (A) & t(sn) & TMS & PS (A) & t (sn) \\
\hline $\mathbf{1}$ & 0.542 & 125 & 1.61 & 0.59 & 118 & 1.72 \\
\hline $\mathbf{2}$ & 0.36 & 525 & 1.08 & 0.38 & 529 & 1.09 \\
\hline $\mathbf{3}$ & 0.177 & 609 & 0.52 & 0.157 & 601 & 0.48 \\
\hline $\mathbf{4}$ & 0.177 & 609 & 0.52 & 0.157 & 601 & 0.48 \\
\hline Amaç fonksiyonu & & & 3,72 & & & 3,77 \\
& & & & & & \\
\hline
\end{tabular}

PSO ve CSA yöntemin geçerliliğini göstermek için bu algoritmalar dört adet aşırı akım rölesinden oluşan güç sistemi üzerinde kıyaslanmıştır. PSO ve CSA algoritması ile bulunan sonuçlar karşılaştırıldığında, CSA algoritmasının PSO algoritmasına göre 0,05 sn'lik daha iyi performans sergilediği görülmüştür. Ama genel olarak PSO ve CSA algoritmalarının yakın sonuçlar verdiği izlenmiştir. Bu çalışmada CSA ile bulunan sonuçların daha optimum olmasından dolayı, DigSilent programında bu sonuçlar aşırı akım rölelerinde kullanılmıştır.

\subsection{CSA Sonuçlarının DigSilent Programında Test Edilmesi}

Bu bölümde daha iyi röle ayar sonuçları elde edilen CSA'ya ait veriler DigSilent ile modellemesi yapılan güç sistemindeki aşırı akım rölelerine girilmiştir. Modellemesi yapılan güç sistemine ait tek hat şaması Şekil 5'de görüldüğ ü gibidir. $\mathrm{Bu}$ tek hat şaması Türkiye İletim Sisteminde yer alan 154/34.5 $\mathrm{kV}$ transformatör merkezlerinin (TM) yapısına benzer şekilde modellenmiştir. Şekil 5' de 1-2-3 nolu aşırı akım röleleri yönsüz röle iken 4 nolu röle yönlü röle olarak benzetimi yapılmıştır.

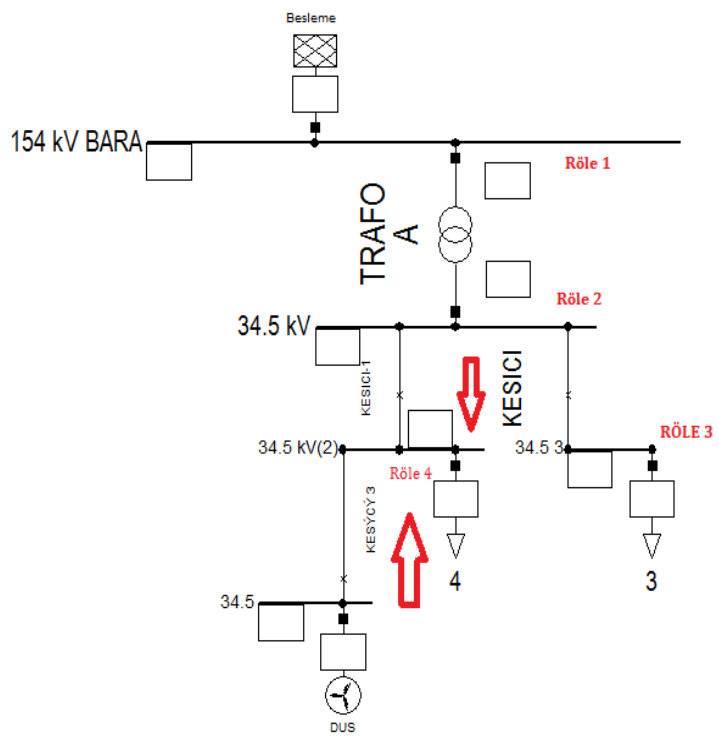

Şekil 5. 154/34.5 kV TM'nin tek hat şeması

Şekil 5'de herhangi bir fiderde arıza oluşması durumunda arıza hem trafo fideri tarafindan hem de üretim fideri tarafından beslenir. Eğer üretim fiderinde kullandığımız aşırı akım rölesi yönsüz ise bu röle de arıza akımını görüp açma verir. Sonuç olarak hem arızalı 
fider hem de üretim fideri devre dışı olur. Bu yüzden bu fiderde, geri yönde arızayı görmemesi için yönlü aşırı akım rölesi kullanılmıştır. Tablo 1'deki CSA'da bulunan optimum röle sonuçları, Şekil 6'daki
DigSilent arayüzü yardımı ile sanal modele girilmiştir. Daha sonra bu modelde 3-faz arıza senaryoları oluşturularak, bu arızalara rölelerin tepkisi analiz edilmiştir.

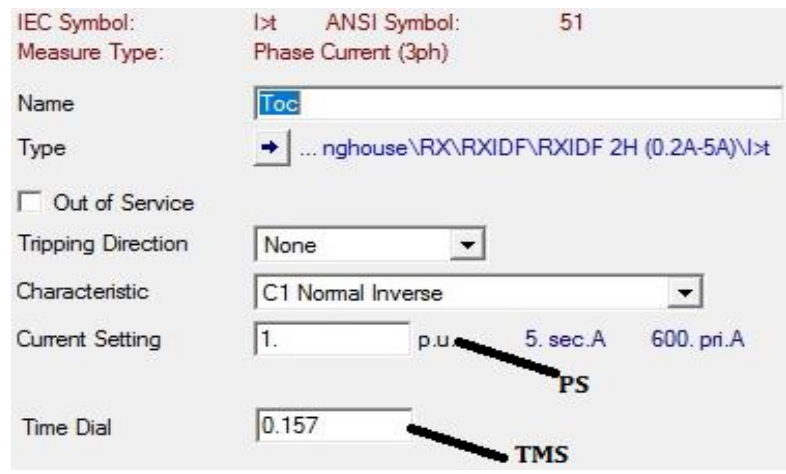

Şekil 6. CSA sonuçlarının DigSilent programında modellenen aşırı akım rölelerine girildiği arayüz.

\subsubsection{Senaryo 1}

$\mathrm{Bu}$ arıza senaryosunda güç trafosunun primer tarafında 3- faz arıza akımı oluşturulsun. Bu arıza akımını (1257 A), güç trafosunun primer tarafında bulunan aşırı akım rölesi, 1.72 sn'de kesmiştir. $\mathrm{Bu}$ rölenin arıza akımını kesmesi Şekil 7'de gösterildiği gibidir.

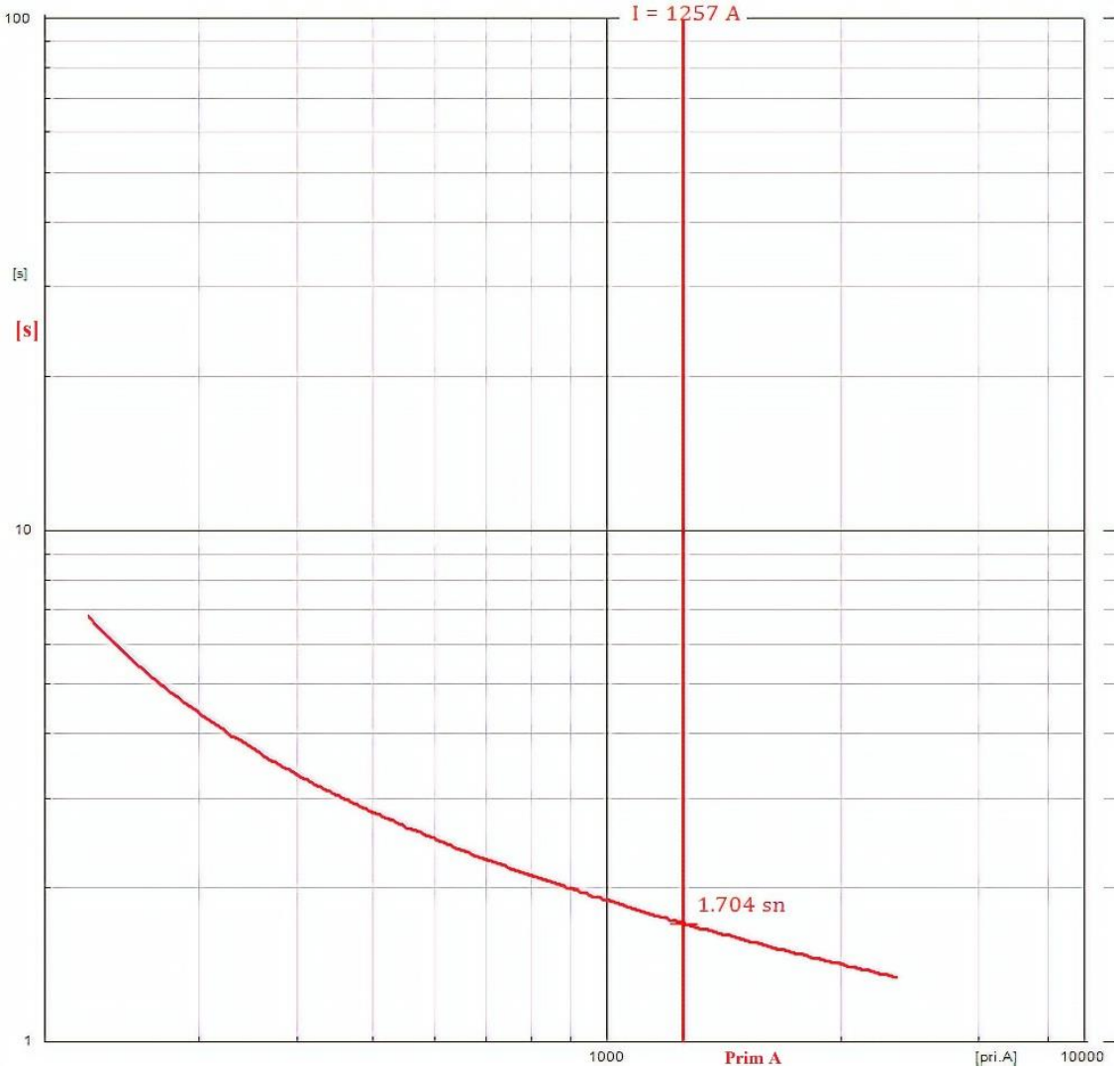

Şekil 7. Röle 1'in 3-faz arıza akımını ters zaman eğrisinde kesmesi

Güç trafosunun sekonder tarafında bulunan $34,5 \mathrm{kV}$ 'luk barada 3 faz arıza akımı oluşturulduğunda; bu arıza akımını ( yaklaşık
5615 A) röle 2, 1.1sn'de kesmiştir. Röle 2'nin bu arıza akımını kesmesi Şekil 8'de gösterildiği gibidir. 


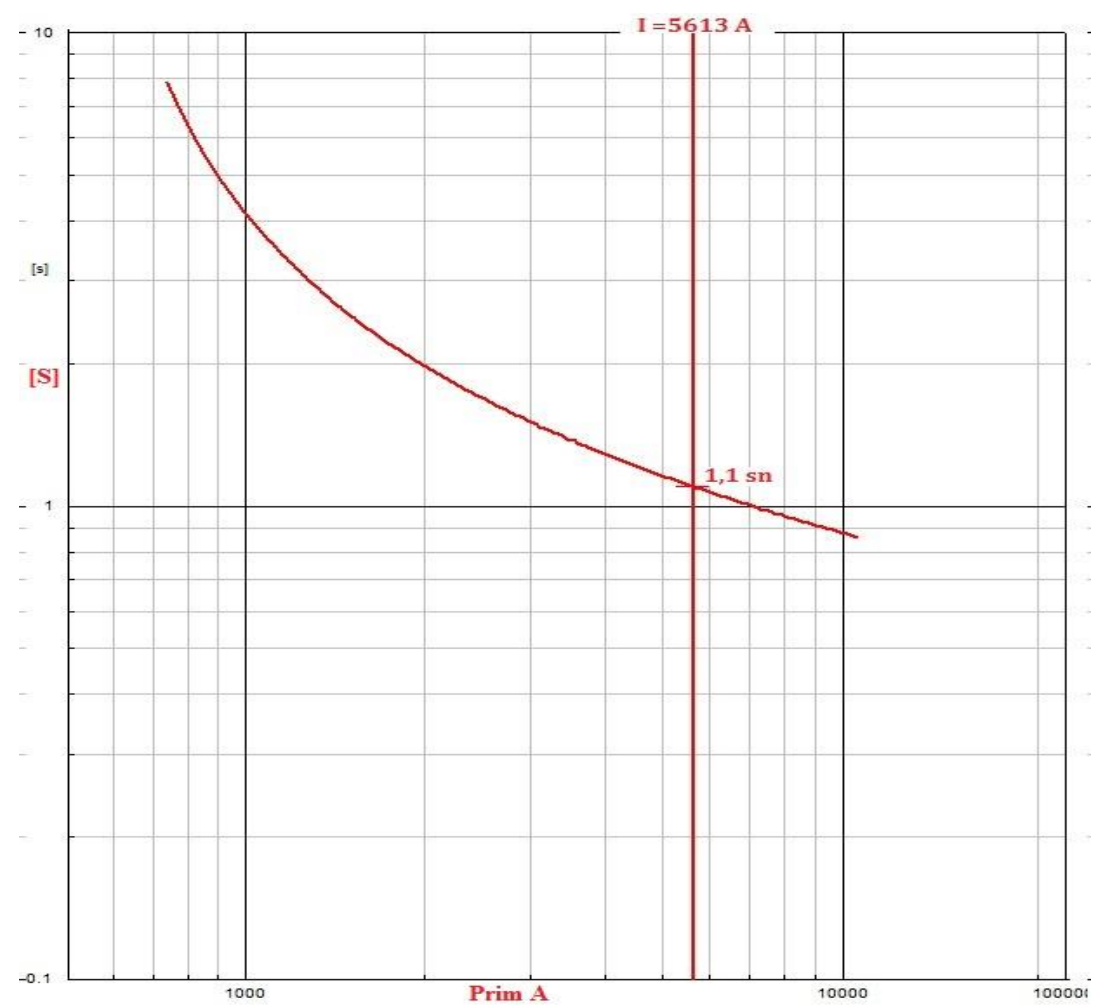

Şekil 8. Röle 2'in 3-faz arıza akımını ters zaman eğrisinde kesmesi

\subsubsection{Senaryo 2}

$\mathrm{Bu}$ arıza senaryosunda röle 3 ve röle 4'ün ayarları aynı olduğu ve röle 4'ün röle 3 'den farklı olarak yön özelliği bulunmasından dolayı bu arıza akım senaryosunda röle 4 ele alınmıştır. Röle 4, yönlü aşırı akım rölesi olduğundan DigSilent programında bu aşırı akım rölesinin yön ayarı Şekil 9'da görüldüğü gibi yapılır. Daha sonra burada ilk olarak üretim santrali (otoprodüktör fideri) tarafında 3-faz arıza akımı oluşturulsun. Bu arıza akımını röle 4'de bulunan aşırı akım rölesi görmez çünkü arıza geri yönde kalmaktadır. Bu durum röle 4 için şekil 10'da görüldüğ̈̈ gibidir. Daha sonra bu fiderde yaklaşık 5614 A arıza akımı oluşturulsun. Bu arıza akımını röle 4, 0.478 sn'de kesmiştir. Rölenin arıza akımını kesmesi Şekil 11'de gösterildiği gibidir.

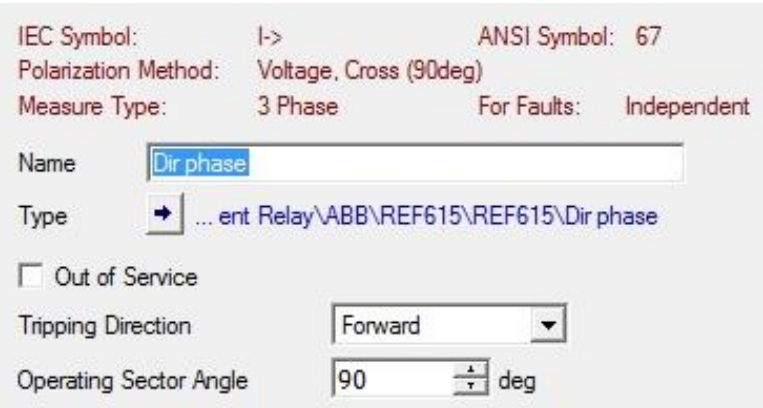

Şekil 9. Röle 4'ün yön ayarı 


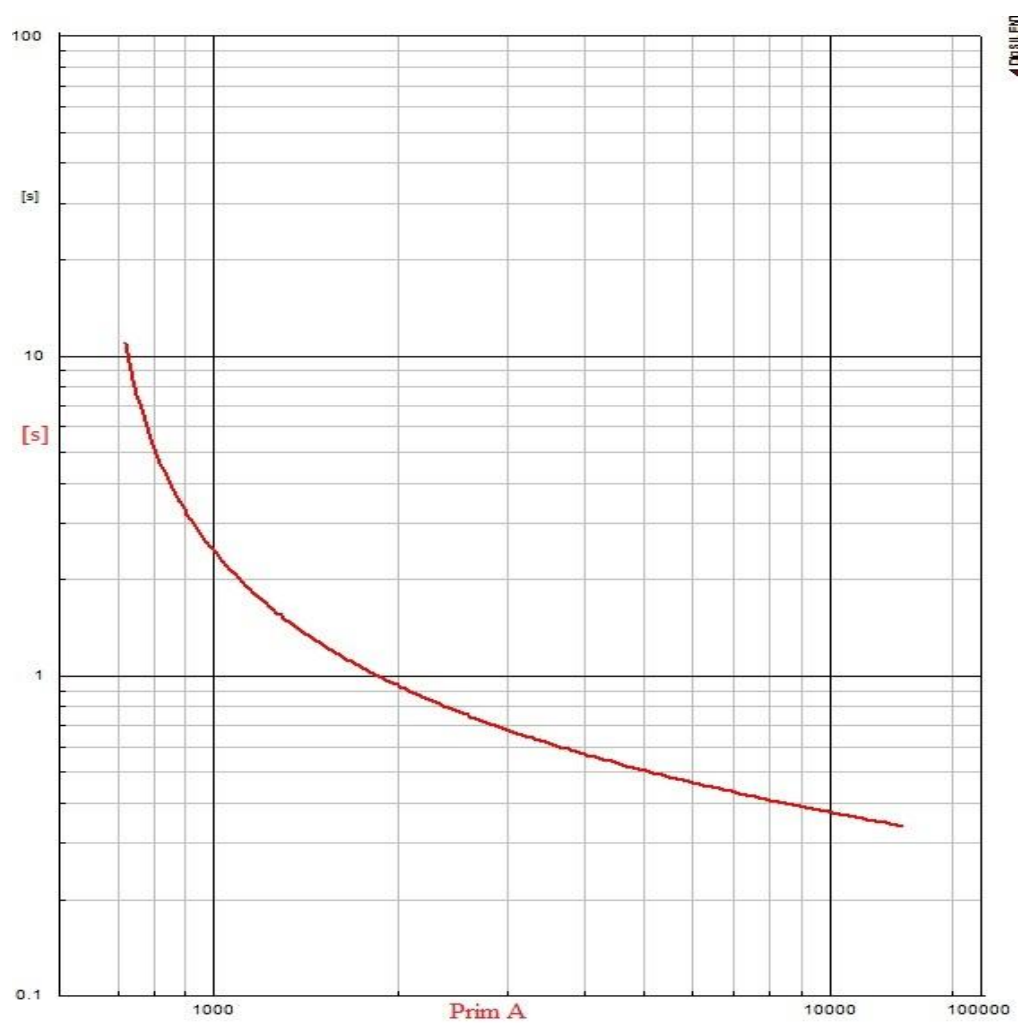

Şekil 10. Röle 4'ün üretim santrali tarafından gelen 3-faz arıza akımını ters zaman eğrisinde görmemesi

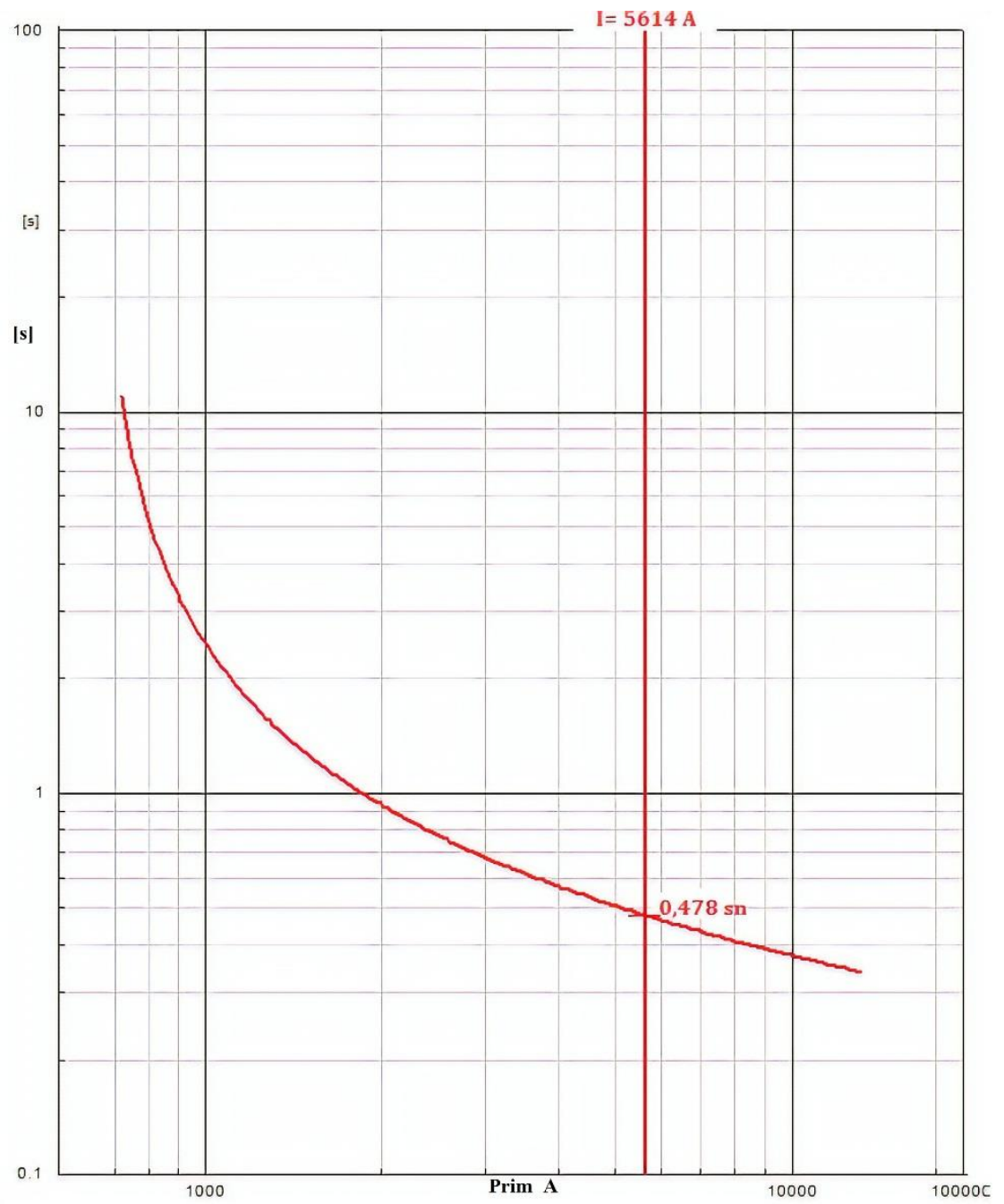

Şekil 11. Röle 4'in 3-faz arıza akımını ters zaman eğrisinde kesmesi 


\section{Sonuçlar}

$\mathrm{Bu}$ yayında 154 / 34.5kV bir transformatör merkezinde aşırı akım röle koordinasyonu konusu ele alınmıştır. Aşırı akım rölelerinin yönlü ve yönsüz özelliği irdelenmiştir. Aşırı akım rölelerinde optimum röle ayarları CSA ve PSO algoritması kullanarak bulunmuştur. Daha sonra bu iki algoritmanın sonuçları karşılaştırılarak daha iyi sonuç veren CSA, DigSilent programında test edilmiştir. Test sonuçları ile bulunan röle ayarlarının uygun sonuçlar ürettiği görülmüştür. Transformatör merkezinde ilk olarak $34.5 \mathrm{kV}$ 'lik fiderler açmıştır. Sonra güç transformatörünün sekonder $(34.5 \mathrm{kV})$ daha sonra primer $(154 \mathrm{kV})$ tarafındaki aşırı akım rölelerinin arıza akımlarını kestiği görülmüştür. Dolayısıyla uygun bir aşırı akım röle koordinasyonu sağlamıştır. $\mathrm{Bu}$ çalışma gerçek zamanlı bir güç sistemine uygulanarak, optimizasyon algoritmaları ile iyi bir koruma yaklaşımı sağlanabilir.

\section{KAYNAKLAR}

Karababa, S., (2013). "Harmoniklerin dijital aşırı akım röleleri üzerine etkisinin incelenmesi", Yayınlanmış Yüksek Lisans Tezi, Yıldız Teknik Üniversitesi Fen Bilimleri Enstitüsü, İstanbul, 10-35

Özel S.A., (2006). "A Genetic Algorithm For Scheduling Jobs On Lines Of Press Machines", Lecture Notes in Computer Science, vol.3743, 535-543.

Özyön, S., Yaşar, C. and Temurtaş, H., (2011). "Harmoni Arama Algoritmasının Çevresel Ekonomik Güç Dağıtım Problemlerine Uygulanması", Çukurova Üniversitesi Mühendislik Mimarlık Fakültesi Dergisi, 26, 65-76.

Chelliah, T. R., Thangaraj, R., Allamsetty, S. and Pant, M., (2014). "Coordination of directional over current relays using opposition based chaotic differential evolution algorithm", International Journal of Electrica Power\&Energy Systems, 55, 341-350.
Zeineldin, H. H., El-Saadany, E. F., and Salama, M. M. A., (2006). "Optimal coordination of overcurrent relay susing a modified particle swarm optimization", Electric Power Systems Research, 76(11), 988-995.

Mazlumi, K., and Motlagh, S. M., 2014. “A novel objective function for directional overcurrent relays coordination", International Journal of EngineeringTransactions B: Applications, 28(2), 205.

Alipour, M.,Teimourzadeh, S. and Seyedi, H., (2015). "Improved group search optimization algorithm for coordination of directional over current relays",Swarm and Evolutionary Computation, 23, 40-49.

Vijayakumar, D. and Nema, R. K., (2008). "A novel optimal setting for directional over current relay coordination using particle swarm optimization", International Journal of Electrical Power and Energy Systems Engineering, 1(4).

Seyyarer, A., Akdağ, O., Hark, C., Karci, A. and Yeroğlu, C. (2017). "Overcurrent relay coordination of $154 / 34,5 \mathrm{kV}$ Hasançelebi substation by league championship algorithm",In Artificial Intelligence and Data Processing Symposium (IDAP), İnönü Üniversitesi, Malatya.

Singh, M., Panigrahi, B. K. and Abhyankar, A. R. (2013). "Optimal coordination of directional over-currentrelays using Teaching Learning-Based Optimization (TLBO) algorithm", International Journal of Electrical Power\&Energy Systems, 50, 33-41.

Pınar, M., (1985). "Elektrik sistemlerinde koruma, röleler ve röle koordinasyonu adlı", Yayınlanmış Yüksek Lisans Tezi, Marmara Üniversitesi, İstanbul, 20-30. 
Enerji Bakanlığı. "Elektrik Şebeke Yönetmeliği”, http://www.epdk.org.tr/TR/DokumanDetay/ Elektrik/Mevzuat/Yonetmelikler/Sebeke, Son erişim tarihi: 11.02.2017

Muangchareon S., Ngaopitakkul A., Bunjongjit S.,Leelajindakrairerk M.,Pothisarn C. and Nawikavatan A., (2013). "Study of Coordination between Protective Devices Comprising Distributed Generation in Distribution System", Energy and Power Engineering, 5(04), 584.

Shi, Y., (2001). "Particle swarm optimization: developments, applications and resources. In evolutionary computation", Proceedings of the 2001 Congress on IEEE, Vol. 1, 81-86.

Askarzadeh, A., (2016). "A novel metaheuristic method for solving constrained engineering optimization problems: crow search algorithm", Computers \& Structures, 169, 112. 